\title{
THE EFFECTIVENESS OF USING THE INFRACOCCYGEAL SACROPEXY IN THE APICAL PROLAPSE TREATMENT
}

\author{
Olivia Ionescu $^{1}$, MD, Univ. Assist. Nicolae Bacalbasa ${ }^{2,5}$, MD, PHD, Nahedd Saba ${ }^{3,4}$, MD, PhD, \\ Prof. Gabriel Banceanu ${ }^{2,3,4}$, MD, PhD \\ ${ }^{1}$ Department of Obstetrics and Gynecology. Breast Center. "Fichtelgebirge" Klinikum. Marktredwitz, \\ Bayern, Germany \\ ${ }^{2}$ Department of Obstetrics and Gynecology, "Carol Davila" University of Medicine and Pharmacy, Bucharest \\ "Department of Obstetrics and Gynecology, "Polizu” Clinical Hospital, Bucharest \\ 4"Alessandrescu-Rusescu" National Institute of Mother and Child Health, Bucharest \\ ${ }^{5}$ Department of Obstetrics and Gynecology, "Dr. Ion Cantacuzino” Clinical Hospital, Bucharest
}

\begin{abstract}
Aim. We purpose to present the current literature on the efficacy of the infracoccygeal sacropexy (IS) or the posterior intravaginal slingplasty (PIS) procedure in women with apical prolapse (AP) who opt for a surgical uterine-sparing method.

Method. The databases Pubmed and Medline have been researched after introducing the key words "uterine prolapse", "apical compartment" and "sacropexy", "sling suspension". We chose the articles published in the german and english language selecting systhematic reviews, methanalyses, retrospective and follow-up studies in which the benefits of the the infracoccygeal sacropexy in women with advanced prolapse of the apical compartment and/or anterior and/or posterior compartment. As it is known that the defects in the compartments are frequently not isolated and appear to be associated one with another, procedures used for anterior or posterior prolapse have also been applied when necessary. Only symptomatic women have undergone operation. The grade of the prolapse has been established using the Pelvic Organ Prolapse Quantitation (POP-Q) system.

Results. After selecting the relevant articles there is insufficient information to support a benefit of the IS technique in the treatment of AP. The recurrence rate in the apical compartment is estimated to be between 14 and $50 \%$. The most important complication of the technique are the vaginal and rectal erosions and, rarely, rectovaginal or urethra-vaginal fistulas. The 3 -year success rate varies between $65 \%$ and $86 \%$ while more than two thirds of women report an improvement in the life-quality. The perioperative morbidity rate is very low.

Conclusion. IS appears to temporary improve the prolapse associated symptomatology but it associated with a very high rate of recurrence as well as high rate of postoperative complications compared to other vaginal techniques with tapes for apical prolapse.
\end{abstract}

Keywords: uterine prolapse, apical compartment, infracoccygeal sacropexy

\section{Abbreviations}

IS = infracoccygeal sacropexy; AP: apical prolapse; PIS = posterior intravaginal slingplasty; POP = prolapse of the pelvic organs; $\mathrm{SSLF}=$ sacrospinous ligament fixation; POP-Q = Pelvic Organ Prolapse Quantitation.

\section{INTRODUCTION}

In spite of the recent progresses in the field of uro-gynecologic surgery for POP, there is still unclear which surgical procedure is the most effective with the most reasonable benefits/ risk ratio (1). It is clear that the decision on one or another surgical method should be optimized depending on the symptomatology, the possible peri-and postoperative risk and not least the patient's life quality, namely the impact of the surgical treatment on the women's daily activities and sexual function (2). We know that the integral theory developed by $\mathrm{P}$. Petros centers itself on the pelvic conjunctive tissue

Corresponding author:

Assist. Nicolae Bacalbasa, MD, PhD, 2 Dimitrie Racovita Street, Bucharest

E-mail: nicolae_bacalbasa@yahoo.ro 
which is incorporated in all of the suspension structures of the pelvic organs (3). Therefore, the surgical treatment of the POP should be grounded on the principle of reestablishing the natural structure of the pelvic attachment and fixation system $(3,4)$. The deterioration of the connective tissue can be rarely identified in one compartment, most frequently the defects of the three vaginal compartments are one with another associated (4). Therefore, the physical examination should be focused on the examination of the ligaments and fascia in the apical, anterior and posterior compartment. Particularly, these applies to the utero-sacral and cardinal ligaments, the recto-vaginal fascia and the central tendon of perineum (5). Most frequently, a normal function of the pelvic structures requires the restoration of all the compartments (6). However, the essential part of the surgery is the repair of the apical compartment, particularly the utero-sacral and cardinal ligaments, as it has been reported that $77 \%$ of the anterior vaginal prolapse is a consequence of the modification of the position of the vaginal apex as well as the of the length of the anterior vaginal wall prolapse (7). Moreover, taking into consideration the POP-Q classification system the position of the apex appear to correlate with the position of the distal part of the anterior wall and namely, an anterior vaginal wall at the level of the introitus is associated with a $5 \mathrm{~cm}$ decrease in the apical support (8).

Although nowadays we consider the success rate and the improvement of the symptomatology requires a precise identification and localization of the pelvic defect, the reported success and recurrence rates do not always correlate with the results of the patient's satisfaction survey (9). There is evidence that emphasize the need to associate the patient's report on symptomatology with an objective measure of the surgical outcome using specific POP-Q measurement system (10). The rates of cure generally are reported after examining the patient's satisfaction survey on bulge symptoms and daily activities $(9,10)$. After identifying and understanding the anatomic modifications and the pathophysiology of the symptomatology, it seems logically to choose a surgical technique that simultaneously normalize the form and the function of the pelvic organs. In this way, it is essential to create a connection between the pelvic muscles and the vagina so that the result of the muscle contraction can be transmitted to the vagina (11). To create the connection between the muscle and the vagina, a new artificial uterosacral ligament to fix the vaginal apex is necessary. If the force transmission is inter- rupted because of an apical fascia defect, the fascia and its defect must be closed $(5,11)$. Basing on this hypothesis, Petros developed in 1997 the infracoocygeal sacropexy (IS) with intravaginal slingplasty also known as posterior intravaginal slingplasty. The main advantages of the technique is its low grade of complexity as well as a low perioperative morbidity rate $(12,13)$. The rate of success has been estimated to be almost $96 \%$ while long-term postoperative complication rate varies between $1.4 \%$ and $8.5 \%$ (14). The purpose of this review is to present the effectiveness, peri- and postoperative complications as well as recurrence rate of the IS technique in the treatment of either vaginal vault or uterine prolapse.

\section{Technique description and short-term results}

The IS or the posterior intravaginal slingplasty method was developed by Petros P.E. and is designed mainly for the treatment of an uterovaginal prolapse grade 2 or more, a vaginal vault prolapse as well as an enterocele or prolapse of the middle compartment. The grade of the prolapse is most frequently assessed using the POP-Q system (11). Summarizing the technique, the patient should be placed in a dorsosacral position. The ischiorectal spaces are dissected using $30 \mathrm{ml} \mathrm{NaCl} 0.9 \%$ solution. The vaginal mucosa will then be longitudinally incised on its posterior wall approximately 1.5 $\mathrm{cm}$ inferior to the cervix. The pararectal spaces will be bilaterally bluntly dissected up to the pelvic part of the levator plate. The kit comprises a polypropylene multifilament tension-free tape which will be inserted bilaterally through a skin incision that is made on the perineum $3 \mathrm{~cm}$ inferior and laterally from anus (11). The needle will be guided through the ischiorectal space towards the ischial spine up until to the ischiococcgygeal muscle which will be penetrated. Further, the tape will be then drawed medially and fixed on the vaginal vault or on the supravaginal portion of the cervix using a non-resorbable suture. The tape can also be adapted an optimal position of the vaginal vault or uterus is achieved. The perineal incision are the sutured with resorbable threads. The ends of the tape remain free. A Folley catheter is required when an anterior colpectomy and colporrhaphy is performed while the finally rectal examination will exclude a possible rectal perforation $(11,15)$.

After examining the results of the studies published in the above mentioned databases, the IS technique appears to be effective with a success rate which vary between $69 \%$ and $98 \%$ (16) after a 
short follow-up period and when combined with other traditional methods for prolapse repair. The initial success rate reported by P. Petros and Farnsworth was 95-98\% (17). This success rate refers to the efficiency on the method in restoring the normal anatomy of the apical compartment which should imply the vaginal apex above the introitus, no pressure or bulge symptomatology, the absence of POP of any grade an no re-interventions (18). Other data revealed a success rate of $58 \%$ after 2 years and 50\% after 3 years which do not demonstrate a significant improvement compared to the old traditional methods (15). Furthermore, compared to the new, modern technique of uterus suspension developed by Saba Nahedd (18), the IS technique has a poor efficiency in terms of recurrence rate - under 1\% in the Saba technique - and short term complications.

The postoperative complication rates is reported to be very low while the vaginal approach which is typically for the IS method allows a shorter recovery time compared to other techniques that use the abdominal route (19). When compared to the sacrospinous ligament fixation (SSLF), the IS technique has been reported to have a lower recurrence rate and namely the postoperative anterior vaginal wall prolapse $(20)$. Some studies $(20,21)$ reported a prevalence rate for anterior vaginal wall prolapse after SSLF between $11 \%$ and $92 \%$ compared to $4.8 \%$ when using the IS technique. However, we can observe that the reported prevalence for the anterior prolapse after SSLF has a very wide spectrum of variation which is owed to the different surgical procedures used in combination with the SSLF (19).

As we know that the deterioration of the connective tissue incorporated in uterosacral ligaments can result lombar pain and dysfunctions in bladder and/or intestinal emptying, it has been demonstrated that a new (artificial) uterosacral ligament created by means of a tunneling device and polypropylene tape significantly reduces the severity of the preoperative symptoms of obstruction which is in concordance with the integral theory of Petros and Ulmsten that centers on the idea that a repair of the anatomical defect results in the normalization of the function $(11,19)$. After evaluating the satisfaction survey after IS, a significant improvement in the prevalence of stress incontinence has also been observed. However, a de novo stress incontinence after SI has also been cited in $0 \%-5 \%$ of cases probably due to the apical prolapse that, when very large, it can produce a functional impairment of the continence mechanism of the urethra (22).

Another aspect that deserves attention is the relative high rate of reported vaginal erosions as a result of using a microporous, inelastic tape which appears to progressively destroy the vaginal mucosa (23). The use of a nylon tape was associated with an $8 \%$ risk of vaginal erosion (17). Other reports (24) suggested that the surgical technique itself increases the risk of vaginal erosion. However, the introduction of multifilament polypropylene tapes has significantly reduced the prevalence of vaginal erosion (16). The prevalence of dyspareunia post IS for apical prolapse appears to be very low - under $2 \%$ - after IS compared to approximately $5 \%$ when a concomitant hysterectomy has been performed. This higher rate can be explained by the shortening of the vaginal length due to posterior colporrhaphy which is generally incorporated in the traditional surgical procedures for POP (25). Other reported short term complications with a very low prevalence include: pararectal abscess, fistula formation, pelvic pains or the need of blood transfusions.

\section{Long-term complications}

The long-term complications after IS for apical prolapse are reported to be very rare (). However, there is evidence for fistula formation 4 years after the operation and namely urethra-vaginal, recto-vaginal, ischio-rectal fistula or gluteo-vaginal (26-28). The latter are very rare and generally have been described as to not have an association with the IS operation although a presentation with gluteo-vaginal fistula has been reported 27 months after operation in the absence of diabetes, immunosuppression or smoking (28). The best method for diagnosis of fistula is the the examination and the magnetic-resonance of the vagina and perineum by seeing a tract between the postero-lateral vaginal wall and the gluteal skin through the ischiorectal space. It has been stated that the cause for a gluteo-vaginal fistula can be the tape itself, especially the multifilamental meshes with pores smaller than 10 micrometers. This impairs the invasion of fibroblasts and of new blood vessels in the tape consequently limiting the adhesion of the mesh into the vaginal tissue (29). This absence of integration into the vaginal tissue initiates the formation of a fistulous tract while the colonization with the vaginal bacteria sustains the progression of the tract until it reaches the perineal (gluteal) skin where the initial incision has been done (30). 


\section{CONCLUSIONS}

In spite of its reasonable success rate with some studies reporting a percentage of $98 \%$, the IS technique appears to be poorly efficient for the restoration of the apical compartment anatomy. It has been reported a lower recurrence rate compared to the SSLF technique but a significantly higher postoperative morbidity and risk of recurrence compared to other vaginal techniques and namely the Saba Nahedd procedure.

\section{BIBLIOGRAFIE}

1. Elkadry E.A., Kenton K.S., FitzGerald M.P. et al. Patient-selected goals: a new perspective on surgical outcome. Am J Obstet Gynecol 2003; 189:1551

2. Dällenbach P., Kaelin-Gambirasio I., Dubuisson J.B., Boulvain M. Risk factors for pelvic organ prolapse repair after hysterectomy. Obstet Gynecol 2007; 110:625.

3. Goeschen K., Petros P.E. Die Integral-Theorie: Ein neuer Weg des Verstehens-Teil 1, Gynecology; 2003a: 8:86-109.

4. Goeschen K., Petros P.E. Die Integral-Theorie: Ein neuer Weg des Verstehens-Teil 2, Gynecology; 2003b: 8:162-169.

5. Goeschen K., Petros P.E. Die Integral-Theorie: Ein neuer Weg des Verstehens-Teil 2, Gynecology; 2003c: 8:246-266

6. Petros P.E, Ulmsten U. An integral theory and its method for the diagnosis and management of female urinary incontinence. Scand $\mathrm{J}$. Urol Nephrol: 1993: 27 (Suppl 153):1-93.

7. Hsu Y., Chen L., Summers A., Ashton-Miller J.A., DeLancey J.O. Anterior vaginal wall length and degree of anterior compartment prolapse seen on dynamic MRI. Int Urogynecol J Pelvic Floor Dysfunct 2008; 19:137-42.

8. Rooney K., Kenton K., Mueller E.R., FitzGerald M.P., Brubaker L. Advanced anterior vaginal wall prolapse is highly correlated with apical prolapse. Am J Obstet Gynecol 2006;195:1837-40

9. Elkadry E.A., Kenton K.S., FitzGerald M.P. et al. Patient-selected goals: a new perspective on surgical outcome. Am J Obstet Gynecol 2003; 189:1551.

10. Hullfish K.L., Bovbjerg V.E., Steers W.D. Patient-centered goals for pelvic floor dysfunction surgery: long-term follow-up. Am J Obstet Gynecol 2004; 191:201.

11. Goeschen K., Petros P., Müller Funogea A., Bratila E., Bratila P., Carstoiu M.M. Planșeul pelvic la femeie. Anatomia funcțională, diagnostic și tratament în acord cu teoria integrativă. Editura Universitară „Carol Davila”, 2016, p.132-141.

12. Petros P.E., Ulmsten U. The development of the intravaginal slingplasty procedure. IVS II-VI. Scand J Urol Nephrol 27 : 1993; Suppl 153. 61-84

13. Petros P.E., Ulmsten U. Surgical principles deriving from the integral theory. Scand J Urol Nephrol 27: Suppl 153, Part III; 1993; 41-49.

14. Farnsworth B.N. Posterior intravaginal slingplasty (Infracoccygeal Sacropexy) for severe posthysterectomy vaginal vault prolapse a preliminary report on efficacy and safety. International Urogynecology Journal and Pelvic Floor Dysfunction, vol. 13, no.1, pp.4-8, 2002.

15. Hino P., Vanspauwen R., Smajda S., Roovers J.P. The Posterior Intravaginal Slingplasty treatment for apical prolapse: 3 years experience in a single centre setting. F, V \& V IN ObGyN, 2010, 2 (1): $1-8$

16. Nyyssônen V., Talvensaari-Mattila A., Santala M. Intravaginal slingplasty sling is associated with increased risk of vaginal erosion. Acta Obstetricia et Gynecologica Scandinavica, vol. 88, no.11, pp.1222-1226,2009.

17. Farnsworth B.N. Posterior intravaginal slingplasty (infracoccygeal sacropexy) for severe posthysterectomy vaginal vault prolapse--a
Moreover, the reported prevalence for vaginal erosion and long term complications especially fistula formation represent an important obstacle that impairs the routine use of this technique for apical prolapse repair. However, some 1 year follow-up studies achieved to show a good improvement in the life quality of patients who have undergone the IS procedure.

preliminary report on efficacy and safety. Int Urogynecol J Pelvic Floor Dysfunct 2002; 13:4-8.

18. Saba N. Concept revoluționar in tratarea prolapsului genital, 4 ani si 4 luni de la aplicarea procedeului Saba Nahedd - 96 de cazuri. http:// revistamedicalmarket.ro/articol/concept-revoluionar-n-tratareaprolapsului-genital-4-ani-i-4-luni-de-la-aplicarea-procedeului-sabanahedd-96-cazuri

19. Lee Y-S, Hyun Han D, Youl Lee J, Kim J.C, Choo M-S, Lee K-S. Anatomical and Functional Outcomes of Posterior Intravaginal Slingplasty for the Treatment of Vaginal Vault or Uterine Prolapse: A Prospective, Multicenter Study. Korean J Urol 2010; 51:187-192

20. Sivaslioglu A.A., Gelisen O., Dolen I., Dede H., Dilbaz S., Haberal A. Posterior sling (infracoccygeal sacropexy):an alternative procedure fo rvaginal vault prolapse. Australian and New Zealand Journal of Obstetrics and Gynaecology, vol. 45, no. 2, pp.159-160,2005.

21. Nieminen K., Huhtala H., Heinonen P.K. Anatomic and functional assessment and risk factors of recurrent prolapse after vaginal sacrospinous fixation. Acta Obstet Gynecol Scand 2003; 82:471-8.

22. Holley R.L., Varner R.E., Gleason B.P., Apffel L.A., Scott S. Recurrent pelvic support defects after sacrospinous ligament fixation for vaginal vault prolapse. J Am Coll Surg 1995; 180:444-8.

23. Bjelic-Radisic V., Hartmann G., Abendstein B., Tamussino K., Riss P.A. The posterior intravaginal slingplasty operation: results of the Austrian registry. Eur J Obstet Gynecol Reprod Biol 2009; 144:88-91.

24. Slack M., Sandhu J.S., Staskin D.R., Grant R.C. In vivo comparison of suburethral sling materials, International Urogynecology Journal and Pelvic Floor Dysfunction, vol.17, no. 2,pp.106-110,2006.

25. Sivaslioglu A.A., Unlubilgin E., Dolen I. The multifilament polypropylene tape erosion trouble: tape structure vs surgical technique. Which one is the cause? International Urogynecology Journaland Pelvic Floor Dysfunction, vol.19, no. 3, pp.417-420, 2008

26. Jordaan D.J., Prollius A., Cronje H.S., Nel M. Posterior intravaginal slingplasty for vaginal prolapse. Int Urogynecol J Pelvic Floor Dysfunct 2006; 17:326-9.

27. Hilger W.S., Cornella J.L. Rectovaginal fi stula after Posterior Intravaginal Slingplasty and polypropylene mesh augmented rectocele repair. Int Urogynecol J Pelvic Floor Dysfunct 2006; 17 : 89 - 92.

28. Prien-Larsen J.C., Hemmingsen L. Long-term outcomes of TVT and IVS operations for treatment of female stress urinary incontinence: monofi lament vs. multifi lament polypropylene tape. Int Urogynecol J Pelvic Floor Dysfunct 2009; 20: 703 - 9 .

29. Sivarajah V., Bello S.O.Z., Yiu C.Y., Oke O. Gluteo-vaginal fistula: a long-term complication of posterior intravaginal slingplasty. BMJ Case Reports 2011; doi:10.1136/bcr.09.2011.4823

30. Riccetto C., Miyaoka R., de Fraga R. et al. Impact of the structure of polypropylene meshes in local tissue reaction: in vivo stereological study. Int Urogynecol J Pelvic Floor Dysfunct 2008; 19 : 1117 - 23

31. Slack M., Sandhu J.S., Staskin D.R. et al. In vivo comparison of suburethral sling materials. Int Urogynecol J Pelvic Floor Dysfunct 2006; $17: 106-10$. 